\title{
O ensino dos anormaes - preocupações em Coimbra e em Portugal no início do século XX
}

\section{Abnormal education as a chief interest in Coimbra and Portugal in the beginning of the XX Century}

\author{
Aires Antunes Diniz*
}

\begin{abstract}
RESUMO
Coimbra, no início do Século XX, era uma cidade muito dinâmica na discussão das idéias pedagógicas. Estava nesse tempo muito bem ligada com a ciência pedagógica que se fazia por todo o mundo. Havia dois jornais pedagógicos que discutiam a profissão e a tecnologia educativa. Notava-se já a presença das idéias da Escola Nova, que estava ligada ao estudo dos desvios da normalidade psicológica. Decroly era bem conhecido e renascia entre nós uma Pedagogia Especial a partir da análise e diagnóstico das deficiências, obrigando à mudança do paradigma pedagógico. Esse processo era mais evidente no ensino dos cegos e dos surdos, mas criou ainda a necessidade social de protecção dos delinqüentes, que eram também crianças e jovens em risco moral. Tudo mostrava Portugal como um país avançado e pioneiro numa pedagogia especial. Foi o que infelizmente um novo tempo político veio obstaculizar, mas isso é já o tema de outra investigação.

Palavras-chave: paradigma pedagógico, deficiência física e psicológica, delinqüência.
\end{abstract}

\footnotetext{
ABSTRACT

In the first years of the XX Century, Coimbra was a very dynamic town in the social and scientific discussion of pedagogical ideas. Coimbra is well

*Professor da Universidade de Coimbra, Portugal. E-mail: adiniz@mail.telepac.pt
} 
linked to an already Global Education Science. In Coimbra, there were two pedagogical journals which discussed not only the teaching profession, but also pedagogical theory and educational practices. We can already see Escola Nova ideas well-linked to the psychological and sociological research about deviance to normal behaviour. Decroly was well-known among us and with him a Special Pedagogy was updated through the analysis and diagnosis of disabilities and handicaps in children and young people, leading to a new educational paradigm. The uprising of a new educational process is clear not only in education of blind and deaf children, but also in the creation of a social protection to the young people, sometimes delinquent or people with only some moral and/or criminal deviance, that are also children and young at moral risk. At that time, Portugal could be seen as a pioneer and an advanced country in Special Education. Unfortunately, a new political era is coming, putting barriers to this future. But this is another idea for a new research.

Key-words: pedagogical paradigm, psychological and physical disability, delinquency.

O paradigma intuicionista baseava-se na idéia de que bastava estruturar tudo em função das lições das coisas para do seu uso resultar uma instrução e uma educação. Mas foi refutado pela evidência de que perante certas anormalidades não funcionava.

Afrânio PEIXото (1936) conta como o Século XIX terminou com a novidade pedagógica que é a educação especial dos anormais, fazendo de seguida o historial da formação desta educação, onde muito se iniciou já no século XVIII. É um movimento de mudança que persistiu e se desenvolveu ao longo do Século XIX, culminando com um acrescento importante que é um plano de recuperação de delinqüentes, onde é determinante a acção de João Bosco (p. 193-196). Mostra como Maria Montessori parte do estudo dos anormais para refazer a pedagogia dos normais (p. 281). Conta ainda como Decroly vai aos Estados Unidos em 1922, mas também à Bolívia, à Argentina e ao Uruguay, onde o conhecem e ouvem. A finalizar o estudo da história da educação, assume que a educação é um acto social, tendente a criar autonomia individual, concluindo que: “A Educação é o caminho que vai do real ao ideal.” (p. 285) 


\section{O nascimento de uma pedagogia especial}

Em 1873, D. António da costa (1900, p. 155) faz uma viagem ao Minho para mostrar num $4^{\circ}$ capítulo como funciona a escola de surdos-mudos em Guimarães. Descreve uma "casa do estudo mais parece uma oficina: machinas, instrumentos, collecções de dinheiro, quadros intuitivos, tudo ali está." (p. 49). Aí, tudo era baseado nas lições das coisas e destinado a desenvolver capacidades profissionais. Mostra-nos uma instituição modelar onde há o padre Aguilar, que usa de muito amor e de muito empenhamento para elevar o nível do sucesso escolar. Faz-nos lembrar Pestalozzi e Froebel, já que educa os deficientes auditivos segundo "os grandes princípios do ensino pela alegria e pelo coração." (p. 47) Conta-nos depois que no ano de 1823, talvez como consequiência da revolução liberal, o ensino dos surdos-mudos iniciou-se com o sueco Pedro Bory, com o governo a dotar a sua escola com $4600 \$ 000$ réis. Em 1828, Bory foge de Portugal aterrado com os acontecimentos políticos. Também em 1832, o subdirector dessa escola, Chrispim da Cunha, é encarcerado por suspeitas de ser constitucional. Logo em 1834, diminuem a autonomia dessa escola ao incorporá-la na Casa Pia. Em 1844, de facto, poupava-se radicalmente na educação dos surdos-mudos. Deixava de haver escola (COSTA, 1900, p. 50). A Escola de surdos-mudos do Padre Aguilar em Guimarães era a única que existia em Portugal. Era uma instituição que faltava desenvolver numa tradição portuguesa de apoio aos deficientes, como PIMENTEl (1919) nos dá conta. Aí, a Pedagogia dos Anormais existe sempre em paralelo com a dos alunos normais, preconizando que se estude previamente a possibilidade da educação destes (p. 40), já esta determinação de capacidades limitadas vai condicionar as possibilidades e as vantagens de uma ortofrenia, uma tecnologia pedagógica especial que melhora as possibilidades correlativas de os educar. Servirá ainda para fazer o reconhecimento da anormalidade, facilitando o trabalho do professor na determinação da Pedagogia de base a aplicar ao aluno normal, permitindo a construção da pedagogia especial que deve ser individualizada para os que chama de anormais de escola. São os retardados de inteligência, os instáveis e os mistos. Esta idéia é o resultado de uma história nacional do Ensino de Anormais, onde tudo se mostra de acordo com os avanços da Medicina e da Psicologia. Sabe-se que os resultados de uma e outra vão sendo introduzidos pragmaticamente nas práticas educativas dos alunos ditos normais, que, por isso, ganham com esta investigação experimental, que procura distinguir o que é comportamento normal do que não é. Aí, a partir dos desvios determina a Pedagogia Normal e a Pedagogia Especial, definindo as necessidades educativas especiais. 
A medicina começava a dar os seus primeiros passos numa especialização em doenças de crianças de que é exemplo o início da prática clínica de uma jovem médica, Sofia Julia Dias, cuja entrada em exercício é saudada com entusiasmo ${ }^{1}$. Era agora preciso adaptar a escola criando classes especiais e institutos especializados. Esta ideia tinha origem na tradução do livro "La Moral à l'École" de Jules РАYOT (1908), que nas páginas 170-171 preconizava a higiene, a educação dos surdos e dos mudos em escolas especiais e frisava a vantagem imensa da sua educação para a comunidade ${ }^{2}$. Divulgava uma educação especial moderna possível na altura e estava virada para uma atitude mais inclusiva. Ao estudar a debilidade mental nas suas repercussões pedagógicas ou comportamentais, indicia que a anormalidade patológica parece ser a grande preocupação do início de Século, criando um conhecimento pedagógico e psicológico progressivamente mais seguro nos seus limites e consequiências pedagógicas.

\section{Análise e diagnóstico das deficiências}

BELL (1880/1883), professor da Faculdade de Medicina de Paris, tinha definido numa sétima categoria de loucuras, as congénitas ou morfológicas (p. 458). Subdividia-as em idiotia, imbecilidade e cretinismo, que considerava educáveis e passíveis de melhoria por uma pedagogia adequada. $\mathrm{O}$ seu pensamento era dominado por uma análise orgânica e fisiológica das doenças mentais, sendo o tratamento preconizado o uso dos diversos fármacos, sendo o uso da pedagogia e da escola uma excepção. Na idiotia e na imbecilidade, a actividade pedagógica seria feita quase sempre através de uma ginástica que desenvolvesse o corpo e uma actividade provavelmente instrutiva que desenvolvesse as faculdades intelectuais, a sensibilidade e a mobilidade. Mostra a maior simpatia pelos enormes e pouco produtivos esforços educativos de alguns educadores dos jovens idiotas, que mostra conhecer bem nas suas componentes, que eram a ginástica, o desenho, o cálculo e a música, mas os resultados alcançados eram medíocres. Por isso, considerava que só se deviam

1 "A Escola", ano 2, n. ${ }^{\circ} 172$, p. 1.

${ }^{2}$ Ver p. 165-167 da tradução de Chagas Franco e 167-169 da edição anónima. 
gastar os escassos recursos pedagógicos com eles após a ter dado uma instrução elementar a todos os jovens normais (p. 828-829). Fazia uma análise mais restrita do cretinismo onde acrescentava a necessidade de uma alimentação substancial (p. 846). Moldaria os professores portugueses pela formação de base e ainda a permanente pela leitura dos jornais.

No início do século XX, as deficiências de carácter psicológico começam a originar a abertura de clínicas e de consultórios destinadas ao seu tratamento. É o caso de Egas Moniz, um político empenhado na defesa dos professores e um médico especializado nas doenças profissionais dos professores e dos alunos, que as podem contrair através do trabalho intelectual ${ }^{3}$. Assim, em 19 de Fevereiro de 1905, como ponto $8^{\circ}$ das reivindicações aprovadas na reunião do Conselho-Directório do professorado, de diversos Centros Escolares e de muitos ilustres professores de varios pontos do paiz ${ }^{4}$, diz-se: "Que á medida que as constituições economicas do paiz o permitirem sejam creados institutos especiais de educação reparadora, destinadas a minorar não só desgraçada condição das crianças feridas nos principais sentidos específicos (cegos e surdos-mudos), mas também das que são lesadas na inteligencia, no sentimento e na conducta." ${ }^{5}$ Era a opinião do médico Egas Moniz, que vivia então em Coimbra e aí, mais do que provavelmente, o inspirador desta forma fisiológica de entender as diversas anormalidades de origem neurológica (PEREIRA; PITA, 2000).

A Educação das Crianças Anormais é tema do editorial de A Escola, em 21 de Junho de 1905, mas o ensino dos anormais, que é afastado do ensino dos normais para permitir mais eficácia na educação destes, que considera uma parte das obrigações do Estado. A razão invocada é que "a sociedade é, em parte, responsavel pelas taras de degenerescencia destes infelizes, porque essas taras são, muitas vezes, um resultado da hereditariedade ou do meio."

Sintonizamo-nos com a França, onde este problema deu já origem a muitos trabalhos ${ }^{6}$. Conclui perante a emergência do problema que é necessário proceder com eles à aplicação de um método rigoroso de investigação das situações. Faz por isso a listagem dos problemas a estudar, que passam pela escolha dos métodos pedagógicos, pela classificação dos anormais educáveis, pelo tipo de estabelecimentos de ensino, pelo modo de recrutamento e habili-

3 "O Ensino", ano 2, n. ${ }^{\circ} 160$, p. 2. Diz $O$ Século num artigo transcrito aqui.

4 "O Ensino", ano 2, n. ${ }^{\circ} 177$, p. 1.

5 "O Ensino", ano 2, n. ${ }^{\circ}$ 177, p. 2.

6 "A Escola", ano 3, n. ${ }^{\circ}$ 178, p. 1. 
tação do pessoal docente. Tudo gira à volta da procura da forma de assegurar a persistência do relativo equilíbrio dos anormais a quando da sua inserção na vida prática ${ }^{7}$.

A classificação dos Anormais segue a classificação de Decroly, onde há:

1 - anormais, por defeito ou lesão orgânica (aleijados, atrofiados, etc,); 2 - anormais, por defeito sensorial (cegos, surdos-mudos, etc.); 3 - anormais, por defeito mental (idiotas, imbecis, etc.); 4 - anormais, por defeito das faculdades afectivas (loucos morais); 5 - anormais, por defeitos particulares do sistema nervoso (epilépticos, etc.); 6 - anormais, por deformação operada pelo meio.

Diz logo a seguir que se vai dedicar ao estudo das anormalidades indicadas pelos números 3,4 e $5^{8}$. O Estudo será por isso continuado por uma análise mais detalhada de cada um dos tipos de crianças consideradas mentalmente anormais, que, avisa, deve ser feito para determinar se é possível conseguir delinear estratégias para a sua escolarização ou educabilidade, que é destinada a restabelecer um equilibrio comprometido, mas não impossível 9 . Explica-se aí que esta classificação está feita por Bourneville, desde 1896. Acrescenta que foi exposta por carta ao director de um estabelecimento de ensino em França. Procura conseguir com esta classificação uma separação clara dos que deverão ir para um hospital e dos que poderão ter uma educação física e moral, que deve ser dirigida para restabelecer um equilíbrio desejado, que não é já impossível de ultrapassar nos limites agora menos estreitos da ciência médica e da pedagogia. Juntas mostram-se já capazes de encetar processos de remediação e de ultrapassagem de algumas deficiências. O diagnóstico médico-pedagógico insere-se assim na procura de uma prática educativa, sempre feita em escolas especiais por pessoal formado que esteja especialmente habilitado ${ }^{10}$. Através deste processo procuram-se cientificamente os meios expeditos, que são planeados curricularmente para melhorar a intervenção dos diversos agentes educativos e também dos médicos na correcção das situações difíceis. São agora programadas no sentido de as corrigir com pragmatismo no decurso do processo pedagógico. Por isso, em 1905, facilita-se a cooperação entre os diversos intervenientes no processo educativo

\footnotetext{
7 "A Escola", ano 3, n. ${ }^{\circ} 179$, p. 1.

8 "A Escola", ano 3, n. ${ }^{\circ} 182$, p. 1.

9 "A Escola", ano 3, n. ${ }^{\circ} 183$, p. 1.

10 "A Escola", ano 3, n. ${ }^{\circ} 185$, p. 1.
} 
através da isenção de selo na correspondência para o inspector, subinspector, pároco, delegado e subdelegado de saúde dos concelhos ${ }^{11}$.

A análise dos problemas de depressão física e intelectual, que afectam as crianças e que, muitas vezes, são começadas por uma disfunção qualquer no lar doméstico, preocupam de forma muito pensada o jornal A Escola. Por isso, propõe-se fazer o estudo das taras, das disposições e das tendências das crianças nas suas páginas ${ }^{12}$. Provavelmente, como resultado da sua influência, pretendia-se discutir no $1^{\circ}$ Congresso Pedagógico da $2^{\mathrm{a}}$ Circunscrição Escolar a "necessidade da fundação de institutos onde se ministre a educação às crianças mentalmente anormaes"13. Define e classifica as doenças como resultado da falta de desenvolvimento, coincidindo ou não com a existência de perturbações nervosas, sendo estas associadas ao enfraquecimento de nutrição, por perturbações oculares, surdez parcial, deformações dos membros, epilepsia, fraqueza intelectual, idiotia ${ }^{14}$.

Este tema faz parte de um manual de pedagogia usado nas escolas normais para formação dos professores. São aí definidas como "crianças que por motivos diversos, uns de ordem fisiológica, outros de ordem psíquica, não podem acompanhar na escola as outras crianças da sua idade. Designa-os por anormais. Para quase todos eles requer o apoio dos médicos. Preconiza classes especiais no caso dos atrasados ligeiros ou dos que têm atrasos por frequência irregular da escola; classes especiais de aperfeiçoamento para os atrasados mentais que classifica em dois grupos, os asténicos e os instáveis. Os cegos, surdos-mudos, gagos, idiotas e imbecis - diz - têm de ser recebidos em institutos próprios, especializados no seu tratamento (LEITÃo, 1923, p. 186187).

No outro lado do Atlântico, nascia ao mesmo tempo também sob o signo da psiquiatria e da análise médica especializada, uma experiência pedagógica no Pavilhão Bourneville no Distrito Federal do Rio de Janeiro. Partia da ideia da inevitabilidade e incurabilidade, determinada pela ciência médica e controlável pela polícia, mas não se opunha à ideia de que eram educáveis e tratáveis (MÜLLER, 2000). A Escola já tinha divulgado o tema aos professores, em 12 de Julho de $1905^{15}$. Por isso, este não deixaria de influenciar o pensa-

\footnotetext{
11 "A Escola", ano 3, n. ${ }^{\circ} 186$, p. 2.

12 "A Escola", ano 3, n. ${ }^{\circ}$ 239, p. 1.

13 "A Escola", ano 3, n. ${ }^{\circ}$ 246, p. 2.

14 "A Escola", ano 3, n. ${ }^{\circ}$ 246, p. 3.

15 "A Escola", ano 3, n. ${ }^{\circ}$ 183, p. 1.
} 
mento e a militância educativa dos professores portugueses, que mostravam nos seus projectos os desejos de dar a conhecer a sua vontade e empenho de resolução dos problemas das Creanças Anormaes. Portugal e o Brasil estavam sintonizados com a prática científica mais actual.

\section{A mudança do paradigma pedagógico}

O estudo das crianças, como nos mostra DRUMMOND (1910), difundia-se por todo o lado e baseava-se por um lado nos dados da medicina e por outro assentava nas práticas pedagógicas, onde Pestalozzi e Froebel eram analisados em função da sua capacidade de intervir através da educação na melhoria das capacidades intelectuais, sociais e profissionais dos deficientes. DRUMMOND afirma o grande interesse das idéias de Froebel pela sua aplicabilidade no desabrochar e no desenvolvimento dos deficientes. Era uma perspectiva desenvolvida por um médico que a partir da análise dos problemas da saúde, vem propor medidas de remedeio ou cura das várias patologias fisiológicas e psicológicas. Ensina-nos a observar e a identificar os problemas e nas terapêuticas estão as práticas pedagógicas, já testadas por Froebel e Pestalozzi e agora estendidas aos problemas das crianças anormais.

Há uma análise dos problemas num capítulo final sobre "Peculiar and exceptional Children", em que identifica o que é possível fazer para os diversos tipos de deficientes. No caso das deficiências mentais, em que não cita Decroly, usa a classificação de Ireland na divisão dos diversos tipos de deficientes. Esta serve para Clarkson fazer a sua divisão em quatro grupos, ficando um quarto grupo para ilogicamente, mas também por razões práticas, que se invocam, juntar diversas patologias, já que o seu estudo parece ser o mais promissor em termos de resultados práticos e de solução mais eficaz. Paradoxalmente deste quarto grupo sincrético extrair-se-ão por análise científica as diversas espécies de deficiências com hipóteses de tratamento médico e/ou educação. Pode ser construída agora uma pedagogia activa diferenciada, que devemos aplicar para obter melhores resultados.

Entre 1908 e 1909, confirmado pelos temas e conteúdos dos dois Congressos Pedagógicos, realizados em Portugal, há uma nítida viragem na forma como se discute a Pedagogia que se deve estudar. No primeiro Silva Barreto ainda diz que "Está-se fazendo pedagogia, o que não é funcção do Congres- 
so". Pede que não se roube tempo à discussão de temas "como o analfabetismo, os dos interesses gerais do professorado, a reforma do ensino moral, etc." (Liga nacional de Instrução, 1909, p. 207). No $1^{\circ}$ Congresso Pedagógico de Instrução Primária e Popular realizado em Abril de 1908 preconizava-se que no cômputo geral se deviam deduzir os anormais como os alienados, idiotas, surdos-mudos, cegos de nascimento, etc. que, de acordo com o Annuario Estatístico de Portugal, referido a 1903, mas só publicado em 1907, eram respectivamente 2868, 3732, 3020 e 5650 (LIGA NACIONAL DE INSTRUÇão, 1909, p. 9). No ano seguinte, Carneiro de Moura (1909) parte da consideração de que ao povo português falta um ideal colectivo e numa comunicação muito larga nos seus muitos objectivos propõe o ensino dos anormais e de assistência aos cegos, surdos-mudos, fracos de espírito e abandonados em todos os municípios, etc. Foi o que o Congresso Trasmontano em 1920 desenvolveu como parte de um processo de desenvolvimento regional (DINIZ, 2003).

No $2^{\circ}$ Congresso, a $4^{a}$ Secção é já dedicada aos Anormais, que se divide nos subtemas ou teses: Anormais Pedagógicos, Anormais Patológicos e Anormais Físicos. Cabe a José CERVAENS Y RODRIGUEz (1909) fazer a primeira intervenção de enquadramento desta questão, em que diz que no caso dos problemas das crianças com retardo intelectual o seu lugar não é nem o Hospital nem a Escola. É um problema cuja não solução de modo atempado e científico as leva mais tarde ao cárcere ou à casas de correcção. Propõe por isso, e como resultado da reflexão com base nos dados científicos, a criação de classes especiais e o tratamento médico de parte destas anormalidades. É desta forma que parte para a descrição das diversas soluções em cada parte do mundo, onde valoriza o papel de Bourneville. Discute os vários conceitos de anormalidade para situar na hereditariedade, nas más condições de vida e nos meios sociais e familiares as razões destas anomalias, que, contudo, a medicina e a educação podem corrigir. É por isso que discute o mau estado da recolha da estatística destes casos, já que se torna assim difícil ou impossível uma qualquer solução racional no sistema de ensino de então, que estava pouco adequado ao real. Para ele, a construção do sistema de ensino dos anormais passa por escolas anexas às escolas comuns, ou escolas autónomas com meio internato e ainda escolas com internato. Estas últimas servirão para eliminar os efeitos perversos de alguns pais. Será assim possível corrigir os efeitos da anormalidade e fazer desenvolver os alunos de acordo com uma pedagogia que não se preocupe em torná-los intelectuais, mas que os prepare para a vida onde possam exercer com competência uma profissão que os faça ou torne felizes e úteis, impedindo que sejam um fardo social. Neste processo de rastreamento dos problemas e da procura de soluções, há a preocupação de 
usar primeiro o método Froebeliano, seguindo-se uma aprendizagem profissional associada a uma ginástica especial para desenvolver os sentidos. Em termos sociais, os pedagogos preocupam-se com a possível intromissão dos charlatães que organizarão estas escolas e querem impedir a perversão de alguns pais que podem procurar estas soluções só porque os libertam dos seus deveres. Na resposta de um sueco a um inglês, que cita, considera-se que é muito mais caro deixar de educar uma destas crianças, deixando-a na ignorância, na miséria e/ou crime.

Faria de Vasconcelos em 1909 está a mostrar o que conheceu pelo estudo, trabalho e investigação na Bélgica. Tudo aí está também a começar. Veio agora a Portugal para elaborar um projecto de organização do Ensino Especial para crianças anormais. Tinha sido convidado para o fazer pelo Conselheiro Ildefonso Marques Mano, o último director geral do Ensino Primário da Monarquia Portuguesa. Mostra conhecer bem o que foi pensado por uma grande variedade de pensadores pedagógicos, que devem trabalhar em equipa com médicos para detectar o que deve ser trabalho pedagógico e o que deve ser trabalho da medicina. Acredita na eficácia da Escola pois alguns dados empíricos comprovam que a percentagem de curados ou melhorados pelos métodos pedagógicos é de 75 a 80 por cento. Na falta de dados estatísticos concretos e correctamente determinados, vai especulando sobre as necessidades sociais neste campo, mas erra as contas. Se considerarmos uma percentagem teórica de $4 \%$ de anormais teríamos para uma população de 6.000 .000 portugueses 240.000 anormais e não os 24.000 que prevê. Divide por isso os anormais em patológicos e pedagógicos, embora nos alerte para as muitas nuances que parecem complicar qualquer análise da realidade.

No primeiro tipo vai fazer a distinção entre os casos graves para os quais se devem criar escolas especiais. Para as anomalias menos graves devem ser criadas e usadas escolas de aperfeiçoamento. Define a partir de Decroly e Yonckeere os anormais pedagógicos cujo atraso de desenvolvimento é provocado por uma longa doença, uma frequência escolar irregular ou por uma fraqueza de espírito de natureza especial. Há aqui a introdução da distinção entre o ignorante e o atrasado, que neste último caso parece em muitos casos ser o resultado perverso de um meio social que provoca atrasos. Mostra aí como a Escola, entendida como organização social, pode provocar disfunções no desenvolvimento das crianças. É o resultado concreto que deriva do seu trabalho sobre: "La Psychologie des Foules Infantiles". Por isso propõe, fundado no pressuposto essencial de que a escola funcione bem, que o atraso nos estudos é um bom indicativo de dificuldades derivadas de falhas na natureza da sua inteligência. Assim um atraso escolar de dois anos deve levar a um 
regime educativo diferente, devendo ser objecto de escolas especiais de aperfeiçoamento. É neste sentido que, baseado na vantagem de criar uma boa organização escolar, nos propõe o seguinte sistema de ensino para os atrasados patológicos e pedagógicos:

$1^{\mathrm{a}}$ - Criação de Asilos Escolas para idiotas e imbecis profundos e de escolas especiais para atrasados mentais e pedagógicos. Estas podem ser escolas com internato ou semi-internato e ainda aulas especiais anexas às escolas primárias, mas separadas destas. $2^{\mathrm{a}}$ - Esta exclusão das escolas normais deve ser determinada por uma comissão médico-pedagógica, que fará o exame médico, psíquico e pedagógico da criança. $3^{\mathrm{a}}$ - A sua distribuição deve ser feita segundo o diagnóstico assim elaborado. As turmas nunca deverão ter mais do que vinte alunos. $4^{\mathrm{a}}$ - $\mathrm{O}$ ensino deve ser simples, concreto, prático, tendencialmente individualizado, adaptado ao seu estado fisiopsíquico, adaptado à sua utilização social. Terá de ser misto, obrigatório e gratuito, com disciplina branda mas firme. Deve valorizar o aspecto físico e o trabalho manual, reduzindo os aspectos teóricos a aulas muito curtas. $5^{\mathrm{a}}$ - Deve ser feito um exame médico-pedagógico semestral, com registos sistemáticos numa caderneta do médico e do pedagogo, que o devem fazer numa colaboração constante. $6^{\mathrm{a}}$ - O Professorado das Escolas Especiais deve ter uma preparação especial, que deve ser estendida aos outros professores quando tal convier. Esta preparação deve ainda ser estendida aos médicos. $7^{\mathrm{a}}$ - Deve organizar-se o serviço estatístico anual das crianças anormais, que devem ter no final uma classificação profissional à saída destas escolas. $8^{\mathrm{a}}$ - Devem ser criadas comissões de protecção pós escolar, que exerçam uma tutela discreta e amiga.

Vem logo a seguir a comunicação de José Barros NOBRE (1909), Professor do Liceu de Castelo Branco, que mostra um bom conhecimento desta problemática num texto seguro. Nota-se a sua preocupação. Prova ainda que o ensino dos anormais dará vantagens substanciais ao estado que o apoiar. Por isso, e no mesmo sentido, valoriza os ganhos do ensino e a necessidade de o estado valorizar todos os cidadãos susceptíveis de algum progresso. Mostra a necessidade de haver um temperamento mais paciente por parte dos professores destas Escolas. Frisa que os professores devem apresentá-los ao exame de $1^{\circ}$ grau do Ensino Primário, embora logo os isente de cumprirem os programas e lhes dê liberdade de ensino para que o possam adequar às dificuldades específicas dos seus alunos. Propõe o seu encaminhamento profissional e familiar por instituições especiais mal termine o internato.

João GONÇALVES (1909) apresenta uma tese sobre os anormais patológicos. Propõe a continuidade de um trabalho atento e individualizado que faça 
o acompanhamento dos anormais por um médico e por um pedagogo, que deve abranger o apoio e o controlo da família, de modo a permitir que se faça a recuperação dos jovens que tenham qualquer deficiência. Justifica isto com a necessidade de controlar o crime juvenil e ainda o dos mais jovens que the parecem em perigo moral por falta de apoio escolar. Para o provar, usa estatísticas elaboradas e tratadas por Alfredo Luiz Lopes que cita no estudo Criminalidade em Portugal (1891-1895). Usa ainda Guyau - Educação e Hereditariedade. Com elas, verifica que os índices de criminalidade aumentam até aos vinte anos. Considera-o fruto de falhas de educação, que devem ser supridas com o uso de vários estabelecimentos educativos. Usa uma expressão que demonstra bem a sua preocupação clínica. É a de ortopedia mental que deve começar bem cedo, logo que detectada, preconizando que seja feita $\log$ aos 2 anos.

Há uma única comunicação na $3^{\mathrm{a}}$ tese da Quarta Secção do Congresso. Refere-se aos Anormais Físicos. Branco Rodrigues apresenta nela um programa de aprendizagem para cegos, assente no Método de Froebel que por isso é de carácter manual. Serve para ultrapassar através do tacto algumas das dificuldades provocadas pela carência do sentido da visão.

\section{O ensino dos cegos}

O Bissemanário “O Ensino" dá notícia em 1 de Março de 1903, p. 2, de uma Escola Profissional de Cegos, instalada no Real Instituto de Lisboa, onde ensinam música, moral e religião, ginástica e geografia. É onde Leon Jamet ensina música pelo sistema Braille. Adolphina Hartivich ensina moral e religião ao cegos. Relata que Alberto Cosmelli ensina ginástica higiénica aos alunos e alunas cegas cuja compleição fraca necessita daqueles exercícios. Alberto de Figueiredo, entusiasmado pela capacidade de aprendizagem dos cegos, ensina Geografia com uns mapas em relevo que a direcção da Escola mandou vir da Suíça. Também aí os alunos e as alunas do Real Instituto vão aprender a escrever em relevo para copiarem livros que irão enriquecer a biblioteca de cegos. É a eles que Branco Rodrigues está gratíssimo já que a instituição que fundou prospera, sendo a primeira do país.

Esta notícia faz parte da permuta de ideias e de informações com o Jornal dos Cegos que assim se inicia. Mais tarde noticia que o Rei aceitou ser 
protector desta Instituição em 15 de Março de $1903^{16}$. Em 17 de Março de 1903, sabemos que Branco Rodrigues, director do Jornal dos Cegos está a fazer a estatística dos cegos, que são tanto os indigentes como os que não o são. Sabemos que enviou listas para todas as freguesias do País e que já recebeu 3000. É sinal que o número de cegos é assombroso. Tanto mais que está ainda à espera de mais listas ${ }^{17}$. Branco Rodrigues anda atarefado a convidar sua Majestade o Rei para Protector da Escola de Cegos do Porto. Consegue-o quando vai agradecer ao Rei o facto de aceite o de Protector da Escola Profissional de Cegos de Lisboa. Aquela Escola do Porto vai ter em Junho de 1903 os seus estatutos aprovados pelo governador civil do Porto, que são perfeitamente idênticos aos de Lisboa. Em qualquer um dos casos, os seus bens são da posse das misericórdias locais, ficando a sua administração financeira também da responsabilidade destas instituições ${ }^{18}$. Através da informação que presta ao Rei sabemos que 2590 párocos já responderam ao inquérito e que a população de cegos é de 5566, dos quais 644 em idade escolar. Só dois párocos se declararam incapazes de o fazer. É o caso do prior de Santa Isabel em Lisboa e o de Cedofeita no Porto. Mas, por outro lado, o benemerito padre Manuel Ferreira Coutinho de Azevedo, pároco da freguesia do Bonfim, uma das mais populosas do país, - diz - já averiguou da existência de 103 cegos de ambos os sexos, estando 43 em idade escolar. Sabemos ainda que vai ao Porto falar com o Governador Civil e com o Provedor da Misericórdia sobre a fundação do novo instituto de cegos, contando já com o apoio real ${ }^{19}$. A Condessa da Azenhaga, informa-se, no aniversário da morte do seu irmão, fazia no dia 20 de Março de 1903 a entrega de 35\$000 réis para serem distribuídos pelos cegos protegidos pelo Jornal dos $\mathrm{Cegos}^{20}$. O apoio aos cegos é ainda feito por cooperativas como a dos estofadores quer por empresas como a Grandela \& Cia. que enviam algumas arrobas de vegetal para os cegos abrirem. É uma maneira de fornecer matéria prima para uma nova indústria criada pela Escola Profissional de $\operatorname{Cegos}^{21}$. Noticia-se ainda que a Maryland School publicou nos Estados Unidos o primeiro Dicionário para Cegos, com letras em relevo, ocupando muito espaço. É por isso composto de 48 volumes com 40000 pala-

\footnotetext{
16 "O Ensino", ano 1, n. ${ }^{\circ} 13$, p. 2.

17 "A Escola", ano 1, n. ${ }^{\circ}$ 6, p. 1.

18 "A Escola", ano 1, n. ${ }^{\circ}$ 29, p. 3.

19 "A Escola", ano 1, n. ${ }^{\circ}$ 9, p. 1.

20 "A Escola", ano 1, n. ${ }^{\circ}$ 9, p. 2.

21 "A Escola", ano 1, n. ${ }^{\circ} 11$, p. 2.
} 
$\operatorname{vras}^{22}$. Através de uma notícia com o título Ensino por cegos a videntes, sabemos que Manuel dos Santos Marques, um cego educado no Instituto de Castelo de Vide, esteve de passagem em Leiria para mostrar como se pode ensinar cegos e videntes com a aplicação de um estojo com caracteres móveis ${ }^{23}$.

Em abril de 1908, o primeiro Congresso Pedagógico presta homenagem à Associação Promotora de Ensino de Cegos que mantém o Asilo Escola António Feliciano de Castilho. Sabe-se que esta já tem mais de 20 anos de existência em que se dedicou à educação mental, profissional e artística dos pequeninos cegos (LIGA NACIONAL DE INSTRUÇão, 1909, p. 182).

Em 1914, o oftalmologista Costa Santos vai analisar os censos e os inquéritos particulares feitos por Branco Rodrigues em 1903 e Dr. MeyerWaldeck em 1904. Mostra assim o nosso atraso em relação aos outros países no tratamento da cegueira e como podíamos avançar, já que, de acordo com o Dr. Meyer-Waldeck, 52\% dos casos eram evitáveis ou curáveis.

\section{O ensino dos surdos}

Em 1875, Joaquim Ferreira Moutinho apresenta um relatório em que tenta iniciar um processo em que se criará uma Escola de Surdos-Mudos no Porto à semelhança da que existe em Guimarães por iniciativa do Padre Aguilar. É fruto do trabalho de propaganda de D. António da Costa que o realizou ao escrever o capítulo sobre a Escola de Guimarães. Comparada com experiências outros países, verifica-se uma sintonia crescente entre os vários países do mundo nos processos educativos, incluindo aqui o Ensino de Deficientes. Neste mesmo trabalho, há a preocupação de recuperar para a vida de trabalho e social os deficientes, que são analisados nas suas possibilidades de recuperação e também nas causas sociais que criaram as condições materiais que lhes provocaram os males físicos de que padecem e lhes provocam estas doenças que os inferiorizam. Mais uma vez, neste como noutros processos educativos, está o Professor de Economia da Academia Politécnica, Rodrigues de Freitas. Em 7 de Agosto $^{24}$, sabemos que existe no Porto para os surdos

\footnotetext{
22 "A Escola", ano 2, n. ${ }^{\circ} 112$, p. 2.

23 "A Escola", ano 3, n. ${ }^{\circ}$ 244, p. 2.

24 "A Escola", ano 1, n. ${ }^{\circ} 46$, p. 3.
} 
mudos o Instituto Araújo Porto. Conta que três surdos-mudos fizeram o exame do ensino primário na Escola de Cedofeita com aproveitamento notável. Mostraram que conseguem fazer tudo como os normais. Numa perspectiva inclusiva, diz que a ciência pedagógica os fará entrar um dia na posse dos seus foros de cidadão. Também se noticiam invenções que permitem aos surdos ter acesso a novos sensações. É o caso do acusticon do inventor Miler Resse Hutchinson que o apresentou numa sessão no Instituto de Nova Iorque para surdos-mudos. Este acontecimento provocou entre eles uma grande surpresa, originando o entusiasmo dos mecenas e militantes educativos, que logo se empenhavam na recolha de fundos para a sua aquisição ${ }^{25}$. Em 23 de Abril de 1908, os congressistas do $1^{\circ}$ Congresso Pedagógico de Instrução Primária e Popular ficam maravilhados pela excelência do Ensino dos SurdosMudos praticado pelo Professor Nicolau Pavão dos Santos. Acontece quando é feita uma apresentação pública dos resultados obtidos (LIGA NACIONAL DE INSTRUÇÃO, 1909, p. 214).

\section{A protecção dos menores delinqüentes}

Portugal integrou-se também aqui nos movimentos internacionais, muitas vezes com influência americana. Este processo é bem conhecido de Alice Pestana que o conta no seu livro póstumo de 1935, editado com prefácio de Bernardino Machado e com vários textos de cidadãos espanhóis. Vê-se que a estimam. Agradecem-lhe assim o esforço com que transferiu para Espanha práticas humanizantes que já tinham sido introduzidas em Portugal pela República. Em 1900, Alice Pestana tinha já alertado para a necessidade de uma educação preventiva da criminalidade que fizesse a tutela rigorosamente científica dos menores, quer dos delinquentes quer dos abandonados, fazendo a integração dos dados antropológicos no processo educativo para que houvesse uma selecção positiva nos seus efeitos.

A República Portuguesa vai ser pioneira em termos ibéricos, uma vez que entende que cada delinquente mais do que um criminoso é um menor em risco perante um mundo cruel que nada lhe dá como educação e que tudo lhe

25 "A Escola", ano 1, n. ${ }^{\circ}$ 10, p. 2. 
exige. Afirma-o com orgulho Alice PESTANA (1935), que tinha casado entretanto com um cidadão espanhol. Nesta nova pátria tem uma actividade impressionante. É a mulher inteligente que observa um mundo perverso que cria os problemas dos menores delinquentes e que ainda lhes aplica penas. Esquece que estas só são aceitáveis como punição para seres adultos que tiveram acesso à educação e a todas as oportunidades para se desenvolverem. É por isso a entusiasta da obra realizada pela República Portuguesa a favor destes menores. Mostra-o no "Protectorado del niño delinquente" em que fez convergir muitas boas vontades na cidade Madrid que parece conhecer bem e onde consegue manter uma obra semelhante a funcionar durante vários anos. Este pioneirismo português numa protecção aos delinquentes de uma forma inclusiva em relação à França, Itália, Espanha e Brasil é confirmado por Sousa e Costa em 1924 e Ruben Landa em 1928, aqui ao frisar o papel de Alice Pestana em Espanha. Comprova-o a narrativa de uma excursão escolar em Maio de 1903, intitulada "Passeio Infantil a Villa Fernando" já que só numa nota de rodapé se informa os leitores de que esta Escola Modelar é uma escola para delinquentes ${ }^{26}$. Mas, o Padre António de Oliveira em 1923 anota o ar tristonho dos jovens citadinos aí internados, embora afirme a excelência dos métodos aí aplicados, que são então renovados. Mostra que conhece bem os ambientes educativos criados nas Escolas de Reeducação. Tenta seguir o percurso profissional dos alunos desta Escola do Trabalho, onde os valores base são Deus, Pátria e Trabalho. Questiona os diversos modos de fazer a reeducação dos delinquentes, preconizando uma atitude preventiva nos meios sociais que provocam a emanação do crime. Propõe que a sociedade se preocupe mais com os filhos do que com os pais. É o resultado de uma análise realista e fundada na experiência pedagógica feita em Caxias que funcionava mais como tutoria do que como prisão. Aí, só a perversão do poder político, associada a uma política de empregos para os amigos, prejudica a função educativa. Nota-se a influência das modernas análises psicológicas e de João Bosco numa análise empenhada. Justifica um apostolado para salvar os menores em perigo moral. Alberto PIMENTEL (1932, p. 68-85) cita só os Decretos e Leis do início da República, esquece tudo o resto, e em particular os progressos na formação de professores, que foram operados vinte e poucos anos antes por interferência directa e pessoal de Faria de Vasconcelos. Como novidade, fala do projecto de decreto lei do Dr. Sérgio Tarouca que criava um Instituto Médico Pedagógico em S. Fiel, Louriçal do Campo (Diário do Governo, $2^{\text {a }}$ série, de 6 de Setembro de 1915).

26 "A Escola", ano 1, n. ${ }^{\circ}$ 28, p. 1-2. 
Em Faria de vASCONCELOS, a questão da anormalidade é algo que o persegue ao longo da vida. Faz sucessivos trabalhos sobre este problema e quase no final da sua vida critica os testes para detecção de desvios significativos de níveis de inteligência entre a população delinquente e a bem comportada. Conclui que a única diferença é que certos crimes estão mais associados à falta de inteligência do que outros. Considera só estar provado que "O combate ao crime para surtir efeitos tem que remontar até à infância, idade capital na formação do indivíduo." (Faria de vasConcelos, 1936, p. 142). Os estudos do subconsciente afloram então. Por isso, conclui que os dados recolhidos põem um problema ainda sem solução. Agora, tudo depende mais da educação moral e cívica dos jovens. Iria investigar posteriormente quais as condições e os meios com que deve ser feito o combate à delinquência. Não o pôde fazer infelizmente.

\section{Conclusões}

A educação especial dos anormaes assume a educação como um acto social, apoiado na psicologia e na sociologia para lhes criar uma maior autonomia individual num mundo real. Ultrapassa o paradigma de Pestalozzi, Froebel e Herbart apoiando-se numa psicopedagogia de base experimental. Aí, os testes clarificam sucessivamente os conceitos de normalidade e anormalidade para os tornarem mais operacionais. Valoriza a Escola como organização social já que, sendo eficiente, pode melhorar o desenvolvimento das crianças. A Educação de deficientes trata agora não só dos deficientes físicos e psicológicos, inclui aos delinquentes e protege os menores em perigo moral. Consequentemente, pensa-se uma educação de deficientes dentro de uma estratégia nacional, que, por sua vez, se insere num processo de desenvolvimento social e económico, com repercussões locais e regionais. 


\section{REFERÊNCIAS}

BALL, B. Leçons sur les maladies mentales. Asselin et $\mathrm{C}^{\mathrm{e}}$, Libraires de la Faculté de Médecine, 1880-1883.

CERVAENS Y RODRIGUEZ, J. Memória. In: CONGRESSO PEDAGÓGICO DE INSTRUÇÃO PRIMÁRIA E POPULAR, 2., Liga Nacional de Instrução, Imprensa Nacional, 1909. Anais... p. 333-345.

COSTA, A. da. No Minho. 2. ed., prefaciada pelo editor Antonio Figueirinhas, 1900.

COSTA SANTOS, S. A cegueira em Portugal. Imprensa da Universidade, 1914.

COSTA, Sousa. Prefácio. In: OLIVEIRA, Padre António. Unamo-nos, Edição do Autor, 1924.

DINIZ, A. A. 1920: O $1^{\circ}$ Congresso Transmontano visto da Guarda, Brigantia, v. 23, (n. 1/2), jan./jun. 2003.

DRUMMOND, W. B. An introduction to child study, [s.l.]: Edward Arnold, 1910.

GONÇALVES, J. Anormaes. In: CONGRESSO PEDAGÓGICO DE INSTRUÇÃO PRIMÁRIA E POPULAR, 2., Liga Nacional de Instrução, Imprensa Nacional, 1909. Anais... p. 363-379.

LANDA, R. La enseñanza secundaria em Portugal. [s.1.]: Imprensa da Universidade, 1928.

LEITÃO, A. Elementos de pedagogia. [s.1.]: Lvmen, 1923.

LIGA NACIONAL DE INSTRUÇÃO. In: CONGRESSO PEDAGÓGICO DE INSTRUÇÃO PRIMÁRIA E POPULAR, 1., 1908, Imprensa Nacional, 1909.

MOURA, C. de. Criação de uma universidade moderna em Lisboa In: CONGRESSO PEDAGÓGICO DE INSTRUÇÃO PRIMÁRIA E POPULAR, 2., Liga Nacional de Instrução, Imprensa Nacional, 1909. Anais... p. 173-176.

MOUTINHO, J. F. Relatório apresentado à Comissão Iniciadora de uma escola para surdos-mudos... e precedido de uma carta de António Luiz Ferreira Girão, lente de Chimica da Academia Polytechnica do Porto, Imprensa Portuguesa, 1875.

MÜLLER, T. A primeira escola especial para creanças anormaes no Distrito Federal: o pavilhão Bourneville (1903-1920), Rev. Brasileira de Educação Especial, v. 6, n. 1, 2000.

NOBRE, J. B. Anormaes em geral. CONGRESSO PEDAGÓGICO DE INSTRUÇÃO PRIMÁRIA E POPULAR, 2., Imprensa Nacional, 1909. Anais... p. 355-361.

OLIVEIRA, A. Deixemos os pais, cuidemos dos filhos. [s.l.]: Edição do Autor, 1923. 
PAYOT, J. La Morale à l'École - Livre de l'Élève. 3. ed., Paris: Armand Colin, $1908^{27}$. PEIXOTO, A. Noções de história da educação. 2. ed., Rio de Janeiro: Editora Nacional, 1936.

PEREIRA, A.; PITA, J. R. (Orgs.). Egas Moniz em livre exame. Coimbra: Minerva, 2000.

PESTANA, A. ${ }^{28}$ Commentarios à vida. (Parceria A. M. Pereira), 1900.

. El protectorado del niño delincuente (un ensayo de educación correccional), Madrid, 1935.

PIMENTEL FILHO, A. Lições de Pedagogia Geral e de História da Educação, v. 1, Livraria Editora Guimarães, 1919.

Lições de Pedagogia Geral e de História da Educação., 2 ed. ref. e amp, Livraria Editora Guimarães, v. 11932.

RODRIGUES, B. Anormaes Físicos. In: CONGRESSO PEDAGÓGICO DE INSTRUÇÃO PRIMÁRIA E POPULAR, 2., Liga Nacional de Instrução, Imprensa Nacional, 1909. Anais... p. 333-345.

VASCONCELOS, F. de. O problema da protecção e educação da infância anormal ${ }^{29}$. In: CONGRESSO PEDAGÓGICO DE INSTRUÇÃO PRIMÁRIA E POPULAR, 2 ., Liga Nacional de Instrução, Imprensa Nacional, 1909. Anais... p. 347-354.

VASCONCELOS, F. de. Problemas Escolares: I e II ${ }^{a}$ série. 2 ed., Seara Nova, 1934. VASCONCELOS, F. de. Delinquência e Inteligência nos adolescentes. Clássica Editora, 1936.

Texto recebido em 10 ago. 2003

Texto aprovado em 11 dez. 2003

${ }^{27}$ Há uma tradução de Chagas Franco para a Livraria Editora Guimarães, Lisboa, s/d e uma outra sem indicação de data, autor ou editora, com divergências na tradução em relação à de Chagas Franco.

${ }^{28}$ Com o pseudónimo Caïel.

${ }^{29}$ Faria de Vasconcelos não deu título à comunicação e por isso uso as suas primeiras palavras como título. 